\title{
Innovation Is the Cornerstone of Sustainable Development of Private University
}

\author{
Huang Jian \\ XiJing University \\ Xi'an 710123, China \\ 565200245@qq.com
}

\begin{abstract}
The fundamental driving force of school development lies in the sense of responsibility, mission and intelligence of the school group. Building a cohesive, diligent and innovative teaching and administrative staff is the key to forming the core competitiveness of the school. Innovation is the main driving force of school development. Education and scientific research is the power source of school innovation, and the fundamental way to create a school brand. In the process of promoting the strategy of "strengthening the university through scientific research", our university has formulated feasible scientific research plans, carried out advanced research projects, and established its own scientific research parks.
\end{abstract}

Keywords-Private university; Core competitiveness; Xijing University; Teaching brand

\section{THE ADVANCED SCHOOL RUNNING IDEA IS THE SOUL OF SCHOOL DEVELOPMENT}

How to make these students stand up to themselves, to stand up the "backbone" of the mind, and to face the beautiful future of life with confidence, is a difficult problem for every private educator. So, at the beginning of our school running, we put forward the concept of sunshine education. The socalled sunshine education concept is to create a harmonious campus, to spread the education sun as much as possible to the mind of the students, to encourage students to develop fully with positive, positive and motivating ways, so that they have the opportunity to become sunny girls and sunshine boys, laying a good foundation for their future development [1-2].

We believe that only by adhering to the concept of sunshine education can we truly achieve the overall development, healthy development and independent development of the students by facing all the students and carrying out the quality education of their children positively and actively. To carry out the idea of sunshine education, we strive to embody the "three sex", that is, the sun is illuminating, everyone is educated, the fairness of education is reflected; the sun is warm, everyone has hope, and the light of education is reflected; photosynthesis, everyone is successful, embodies the growth of education. In order to carry out the fairness, brightness and growth of the sunshine education, in the practice of education, we require all the educators to face the whole, be indistinct, spread love to every child's heart, pay attention to the overall development of every child, and correctly apply the positive means of awakening, appreciation and encouragement, and the spring wind Rain, moisten things silently, return the happiness of growth back to the children, encourage the healthy development of every student, improve the quality of life of the children, let the students grow up in the new and new, learn to be strong in the setbacks, succeed in defeating the failure, make a leap on the basis of success, and promote every one Children's self-development.

The sunshine education in our school is mainly carried out through the implementation of the "35" sunshine moral education project, that is, through the "35" series of moral education books compiled by the school as the school-based teaching materials, creating a characteristic moral education curriculum system, carrying out full personnel responsibility system, carrying out rich and colorful moral education series activities, and building rich connotation. The thick campus culture, the creation of the unique charm of the sunshine apartment, the perfection of the seven color sunshine awards system and the moral evaluation system and other ways to complete the implementation. Among them, our student's "colorful sunshine series Award" has played a positive role in encouraging students to develop independently and develop their own characteristics. Good students unique lies in: it is a series of award for outstanding projects, not only, also for expertise, more progress award. The students' personal award has set up the star award, the sunshine award, the seven color prize and the special prize, and the class collective prize has set up the class prize and the special class award. The two is the process of awarding the prize. Student self declaration, class collective review, departmental examination and approval, School Award recognition, the whole award process is a process of self education for students. The three is the wide. Good students do not set series of award winning places, a variety of awards and report it. Over the past 3 years, the number of students winning the prize has exceeded 5000, and the winning area has reached over $90 \%$ [3]. For the excellent students, the school also awarded the president special award. This way of breaking the Convention and focusing on encouragement has effectively promoted the diversified development of students.

Do a good job in the sunshine education at the same time, our school to strengthen students' daily behavior standards and class school construction management. To carry out the responsibility system for the whole process of education, the school administrators and staff members and staff on the first 
week of the week on Tuesday, the centralized time unified the examination and supervision of the implementation of the school students' behavior norms; the moral tutor system, all moral tutors use an early reading time to meet their own moral education, to understand their last week. Learning, thinking, life and other aspects of the situation, students can also pass this opportunity to tell their own ideas and requirements in time to tell their moral tutors, such as fixed, fixed, regular moral guidance, both targeted and effective; improve the evaluation system of students' conduct assessment, and report the term of the week to the semester. The conclusion ensures the standardization and continuity of moral education management [4-5].

\section{GOOD TEACHERS ARE THE KEY TO THE DEVELOPMENT OF SCHOOL}

The fundamental driving force of school development lies in the sense of responsibility, mission and intelligence of the school group. Building a cohesive force, fighting force and innovative teaching staff is the key to form the core competitiveness of a school.

\section{A. Advocate good spirit and team cohesion.}

The teachers in private university are generally not stable enough. The reasons may be many, but the treatment is not high and no sense of belonging is the main reason. Teachers in private university come from all sides, and their educational backgrounds, work experience and motivation are different. Their treatment is not good for the public school. If the faculty and staff have no ideological and spiritual conversion to the school concept, it is impossible for him to settle down, and it is impossible to participate in the reform activities of the school and even to the daily education and teaching activities in all directions, whole processes and wholeheartedly. Integrate their interests and school interests to achieve the value pursuit of personal and team development. Therefore, in order to ensure the stability of teachers, schools must be cohesive. The generation of cohesion depends on the soul of schools. The soul of xijing's university is the school's vigorous advocacy of "xijing spirit" based on the concept of "career outlook, service concept and team view". The spirit of blessing is manifested in the career outlook, which is the spiritual realm of love, loyalty and fighting for the private education. In the service view, it has a strong sense of quality, service consciousness and benefit consciousness for the work of the school. The desire for mutual promotion and common development.

The advocacy and practice of "fuking spirit" will make fuking the Faculty of fuking a school in love and work. In the case of common conditions, heavy tasks and general treatment, it is possible to make enterprising and brave and fight. In 9 years, there are 8 classes and more than 300 teachers and students in a high school and junior high school at that time. It has formed more than 2000 teachers and students. All this fully shows that "xijing spirit" is the key to ensure teachers' relative stability and promote the rapid development of schools.

\section{B. Promote the development of teachers' professionalization and enhance the team's fighting capacity.}

A good wind can be taken to send me to the blue clouds. In advocating good spirit at the same time, our efforts to promote the professional development of teachers, enhance the combat effectiveness of the team. After deciding the way of running a school, cadres are the decisive factors. The first to grasp the team is to grasp the cadres and grasp the backbone. Our school has carried out the "321" charge program among cadres and key teachers. Each person will read 30 teaching papers and 2 books of education each year, and then write 1 research papers or study summaries in connection with the actual situation. On this basis, we also grasp the post training of cadres. In 2007, the school sent three vice presidents and two school councilors, and participated in the study of the training class of the president of the private university (Yuan Chang), which was held in Shenzhen and Guangdong respectively. During his study, Wang Shunxin, the principal of the junior high school, contacted the actual thinking and put forward the problems and Countermeasures to further improve the quality of junior high school education. The investigation report written by $\mathrm{Ma}$ Hongping, the principal of the high school, was appraised as the outstanding thesis of the principal's study class, and the paper of the standing president, Weng Yuyan, in the headmaster's training class, "how to be well run by the people" CEO of the school won the 2007 "Guangdong first private school running forum" Excellent Thesis Award. The enhancement of managers' quality has effectively improved the scientificity and executive power of school running decisions.

To promote teachers' professional development is to satisfy teachers' sense of achievement and happiness. Though it is very difficult, we still have to work hard to do it. With the increasing speed of the knowledge renewal cycle, especially the continuous development of computer network technology, teachers can only improve their comprehensive quality to meet the needs of their own, school and social development. In order to promote the professional development of teachers, we strive to create a relaxed and harmonious humanistic atmosphere for teachers, establish a long-term mechanism for training and study, and provide a broad platform for self development.

Create a relaxed and harmonious atmosphere of humanity. A relaxed and harmonious cultural atmosphere can make teachers live freely and enjoy themselves. Teachers are a special group with strong self-esteem. Teachers are a special profession with strong autonomy. They want more respect and care. Only by setting up a "teacher based" management concept and creating a relaxed working environment and a harmonious humanistic atmosphere can the leadership of the school arouse their enthusiasm for work. Only when they want to do something, can they go to work and do well at last. Fuking universitys to carry out a two-way choice, fully respect the teachers' own work will, the implementation of the public, fully respect the teachers' right to know, the implementation of the goal management, fully respect their labor. There is a popular saying in xijing, that is, let teachers do things with two hands, not one hand, and one hand against anything else. 


\section{Activating the personnel mechanism of private schools to ensure team creativity}

The management level of a school can best reflect the running level of a school. xijing university gives full play to the advantages of the management system of private schools, taking high efficiency as the principle, flattening as the characteristics, taking competition as the mechanism, innovating management ideas, so that the school presents a new management pattern with quality as the core and service as the purpose. This management system has optimized the allocation of school resources and ensured the team's innovative vitality.

Establishing the first person responsibility system and strengthening execution. xijingwai School fully implements the system of the first responsible person, that is, the principal is the first responsible person for running the school as a whole, the Deputy principal in charge of the Middle School of the high school and the directors of various functional departments are the first responsible person in charge of the school's various functions, and the directors of each grade and class are the first responsible person for the overall work of all grades and classes. Under this premise, the school management framework forms a "center" and "two systems" mode. The "one center" is centered on the quality of education and the efficiency of running a school; the "two systems" are the quality control system with the junior middle school as the educational entity and the service management system with the functional departments as the service entity, so as to realize the combination of each piece and complement each other's advantages, reduce the cost of management, improve the efficiency of management and overcome many problems. Management $=$ unmanaged, multi person responsibility $=$ unaccountable management disadvantages. The management system of xijingwai University, which is based on the first responsible person system, achieves clear objectives, fulfills responsibilities and works in place to enhance the execution and competitiveness of the school.

Establish appointment contract system and optimize staff team. xijing university strictly implements two way contract appointment system. The flexible employment mechanism ensures the vigorous and orderly flow of talents. There is no such thing as "doing a good job well, not worrying about work and wages". The appointment system not only fully respects the wishes and choices of the faculty and staff, but also enables the faculty and staff to compete for their satisfactory jobs through various comparisons. The school also achieves the employment of the best, and achieves the optimization of the combination.

At the same time, the two-way contract appointment system of xijing University also maximizes the protection of the rights and interests of the contracted faculty and staff. For example, the school handled medical, pension, unemployment and other social insurance for all the contracted staff; actively handled the transfer procedures for more than 70 qualified staff; joined the Shenzhen Rural Commercial Bank to launch the xijing university Staff Personal Loan Discount Scheme, and implemented the second refund of xijing staff. The rest plan and gradual improvement of teachers' treatment have effectively solved the worries of teachers and staff members.

Implementing evaluation and reward mechanism to stimulate innovation vitality. Objective and fair evaluation of teaching staff is an important part of the school management system. For this reason, xijing university has formulated and continuously improved a set of qualitative and quantitative evaluation system. The teaching Congress evaluates school councilors, school councillors evaluates middle-level cadres, heads of functional departments and evaluation staff of service objects, grade directors and subject group leaders evaluates teachers, and students evaluates subject teachers, class teachers, moral education instructors and self-evaluation. The multi-level and multi-angle evaluation embodies the reliability and validity of the evaluation, further activates the management mechanism and ensures the benign operation of the management system.

Student apartment is an important position to promote quality education in an all-round way, and is the "second classroom" of students'learning and life. The management and service of student apartments are playing an increasingly important role in the school education system, and their functions are becoming more and more prominent. The Sunshine Apartment was established in Fujingwai University, combining with the characteristics of the management and service of the students'apartments, to construct a platform for students' self-education, and to effectively cultivate students' good ideological and moral character and behavior habits. With the expansion of school scale, the number of students living in apartments has reached 900, which makes the management, service and education of apartments more difficult. In order to build a sunshine apartment, to ensure the safety of the apartment, this year, the school has increased the number of apartment managers, the original multiple management into one management, enhanced the overall function of management. Living quarters to strengthen the training of life teachers, strengthen their sense of post, service, safety awareness. At the same time, strengthen the safety education of students and the cultivation of self-care ability, give full play to the special role of apartments in educating people, has been praised by students' parents.

Build a safe campus. We will implement the system of responsible persons for safety, build a safe and harmonious campus, and put an end to major safety accidents and criminal incidents. Since this year, the school has undergone three major safety inspections at the city level. According to the rectification requirements, the Living Office and the General Affairs Office have further strengthened the management of student apartments and school canteens. Schools have set up security directors and full-time security personnel, strictly enforce the rules and regulations of security work, strengthen coordination with property management departments, improve the school's monitoring system, formulate various types of campus emergency plans, and strengthen the effectiveness of public security departments, urban management departments, community neighborhood committees and other units under their jurisdiction. Cooperation to ensure the safety of campus and surrounding environment. At the same time, the school hired two police officers from Jingtian Police Station and 
Armed Police Fire Brigade to give special lectures on safety and legal system, held fire drills in teaching buildings, and strengthened teachers and students'legal concept, safety awareness and self-help ability. The school has maintained a record of zero safety accident rate for nine consecutive years, which is fully affirmed by the higher authorities.

\section{SUMMARY}

The management level of a school can best reflect the running level of a school. xijing university's give full play to the advantages of the management system of private university, with the principle of high efficiency as the principle, the flat as the characteristic, the competition as the mechanism, the innovation management idea, and the school presents the new management pattern with the quality as the core and the service for the purpose. This management system optimizes the allocation of school resources and ensures the team's innovative vitality.

\section{REFERENCE}

[1] Wen Dong Mao. On the non contradiction between public welfare and business viability of private education [J]. review of education in Peking University, 2004, 2 (1):43-48.

[2] Fanxianzuo. Financial and cost management of education [M]. Shanghai: East China Normal University press, 2004.

[3] Lv. Yan. The balance or profit distribution of private educational institutions [J]. Journal of Henan College of Finance and Taxation, 2004, 18 (1): $26-27$.

[4] The law of the people's Republic of China on education promotion is adopted at the thirty-first session of the Standing Committee of the Ninth National People's Congress 2002.

[5] Ministry of education. Financial system for primary and secondary schools, 2013. 